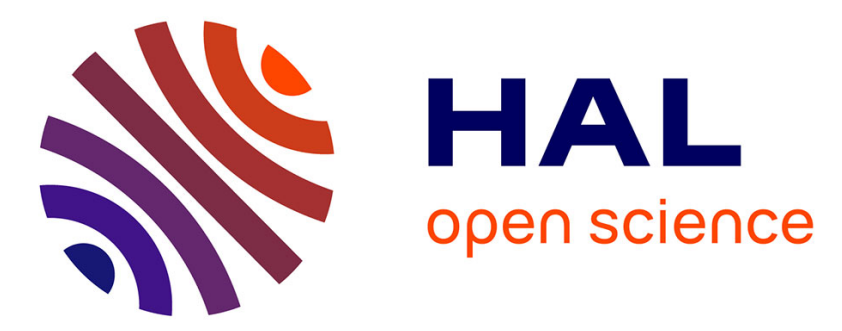

\title{
Ex situ and in situ investigation of protein/exopolysaccharide complex in Porphyridium cruentum biomass resuspension
}

Thierry Tran, Céline Lafarge, Pascale Winckler, Rémi Pradelles, Nathalie Cayot, Camille Loupiac

\section{To cite this version:}

Thierry Tran, Céline Lafarge, Pascale Winckler, Rémi Pradelles, Nathalie Cayot, et al.. Ex situ and in situ investigation of protein/exopolysaccharide complex in Porphyridium cruentum biomass resuspension. Algal Research - Biomass, Biofuels and Bioproducts, 2019, 41, pp.101544. 10.1016/j.algal.2019.101544 . hal-02173261

\section{HAL Id: hal-02173261 \\ https://u-bourgogne.hal.science/hal-02173261}

Submitted on 25 Oct 2021

HAL is a multi-disciplinary open access archive for the deposit and dissemination of scientific research documents, whether they are published or not. The documents may come from teaching and research institutions in France or abroad, or from public or private research centers.
L'archive ouverte pluridisciplinaire HAL, est destinée au dépôt et à la diffusion de documents scientifiques de niveau recherche, publiés ou non, émanant des établissements d'enseignement et de recherche français ou étrangers, des laboratoires publics ou privés.

\section{(ㄷ)(1) $\$$}

Distributed under a Creative Commons Attribution - NonCommerciall 4.0 International 


\section{Ex situ and in situ investigation of protein / exopolysaccharide complex in Porphyridium cruentum biomass resuspension}

Thierry $\operatorname{Tran}^{l}$, Céline Lafarge ${ }^{l}$, Pascale Winckler ${ }^{l, 2}$, Rémi Pradelles ${ }^{3}$, Nathalie Cayot $^{l * 1}$, Camille Loupiac $^{l}$

1 Univ. Bourgogne Franche-Comté, AgroSup Dijon, PAM UMR A 02.102, F-21000 Dijon, France

${ }^{2}$ Dimacell Imaging Facility, AgroSup Dijon, INRA, Univ. Bourgogne Franche-Comté, F21000 Dijon, France

${ }^{3}$ Microphyt, 713, route de Mudaison, 34670 Baillargue

Journal: Algal research

${ }^{* 11}$ Corresponding author. Nathalie Cayot ph. +33 380774085 ; e-mail address : nathalie.cayot@agrosupdijon.fr Abbreviations: APC (allophycocyanin), B-PE (B-phycoerythrin), CLSM (confocal laser scanning microscopy), EPS (exopolysaccharide), HPH (high pressure homogenizer), PBR (photobioreactor), R-PC (R-phycocyanin). 


\section{Introduction}

The extraction of B-phycoerythrin from Porphyridium cruentum has been intensively investigated [1-3] because this pigment protein is used as fluorescent biomarker [4]. P cruentum is a spherical unicellular red alga (Rhodophyta) without an organized cell wall [5]. P. cruentum's ultrastructure was firstly determined using electron microscopy from 1959 [6,7]. This microalga is photoautotrophic and its photosynthesis is achieved by the lamellashaped thylakoids that host the photosynthetic material [6]. But besides chlorophyll, P. cruentum hosts numerous fluorescent substances such as phycobiliproteins including Bphycoerythrin, R-phycocyanin and allophycocyanin whose absorption and fluorescent properties have been well studied [8,9]. Those molecules are all located in the thylakoids: the phycobiliproteins are organized in a hemispherical structure called phycobilisome located on the outside of this thylakoid membrane. The chlorophyll is on the inside part of the thylakoid [10,11]. Quantitatively, there is roughly ten times more B-phycoerythrin than Rphycoerythrin and allophycocyanin separately in P. cruentum [12]. This microalga is also encapsulated in a sheath generated by the continuous secretion of anionic sulfated exopolysaccharides (EPS) [13-16]. Their composition has been determined. They host a high diversity of sugar residues including D-xylose, D- and L-galactose, D-glucose, D-glucuronic acids $[14,17,18]$, and are covalently linked to sulfate groups and peptides [19]. The composition of those EPS are dependent on the cultural conditions of microalgae [20-22].

The EPS are often seen as an obstacle to the extraction and purification of B-phycoerythrin (B-PE). In fact, the interaction between proteins and EPS can lead to a loss of extraction yield. Some studies often highlighted the difficulty to isolate B-PE from EPS [23] and even suggested the existence of B-PE / EPS complexes [24]. To our knowledge, no research was published on the topic of B-PE / EPS interactions, and even less in situ on microalgae biomass. The interactions between proteins such as bovine serum albumin, ovalbumin, whey 
protein and sulfated anionic polysaccharides (carrageenans, dextran sulfate) have been extensively investigated in model systems by using calorimetry, spectroscopy, or rheology. Those studies have shown that these interactions were electrostatic interactions induced by the polysaccharide charge density at low ionic strength [25]. Those complexes could then be dissociated by the addition of salt. The main parameters influencing these associations are $\mathrm{pH}$, ionic strength and temperature [25-32].

In order to better understand B-PE / EPS interactions, the present study aimed to examine the behavior of B-PE towards EPS in resuspension of P. cruentum biomass submitted to several $\mathrm{pH}$ and ionic strengths.

Moreover, following the approach of overcoming the obstacle of the EPS interactions during the extraction of B-PE, two extraction processes were tested: successive macerations and high pressure homogenizer treatment. This choice is based firstly on the hypothesis that those methods can reduce the interaction between B-PE and EPS and secondly on their ability to be up scaled for industrial purpose. These methods were also chosen because they were mechanical (and non-chemical or biological), and were supposed to limit the denaturation of protein pigments.

As maceration is a simple and common extraction method, it was carried out as a single step in a lot of reported studies $[1,3,33,34]$ and did not allow to reduce the amount of EPS in the sample. On the contrary, successive macerations are expected to solubilize and dilute the EPS after each step, thus allowing further extraction of B-PE. This is the modality chosen for this study by using three successive macerations.

High pressure homogenizer is a more aggressive extraction method since it is expected to disrupt complexes along with the cells themselves by applying shear forces on the system. High pressure homogenizer treatments $(\mathrm{HPH})$ for the extraction of B-PE from P. cruentum 
have already been studied by Jubeau et al.[24]. In this work, the effect of HPH with one step and two steps was studied. After the use of these two methods of extraction (maceration and HPH), the B-PE content was determined by spectrophotometry. More recently, the use of high hydrostatic pressure was applied to study the extraction of B-PE [35].

In the present work, we used microscopy to follow the B-PE and bound EPS in situ. The advantage to work with $P$. cruentum is that this microalgae offers interesting conditions for confocal microscopy because of the size of its cells of 7 to $16 \mu \mathrm{m}[6]$ and, the fluorescence properties of phycobiliproteins and chlorophyll with excitation maximum wavelengths ranging from 545 to $675 \mathrm{~nm}$ with distinct emission peaks [8]. Confocal laser scanning microscopy (CLSM) allows the simultaneous observation of transmitted light and fluorescence signal based on one excitation wavelength. A spectral detection enables differentiation of fluorescent emission into several wavelength ranges [36-39]. CLSM was already reported as a powerful method to study the phycobiliproteins composition of cells in situ and follow the changes in intracellular phycobiliprotein content through the life cycle of another photosynthetic microorganism (Nostoc punctiforme) [36]. Then, to localize and study the B-PE / EPS complexes, the native autofluorescent compounds of the cells and fluorescence markers for the EPS (bound or not) were used.

To sum-up, in order to better understand the B-PE / EPS interactions, the present study aimed to examine these interactions ex situ and in situ in resuspension of P. cruentum biomass submitted to several $\mathrm{pH}$, ionic strengths and using two different extraction processes.

\section{Materials and methods}

\subsection{Biological material and culture conditions}


The marine Rhodophyta Porphyridium cruentum (1380-1C) was provided by the SAG Culture Collection (Göttingen, Germany). The microalga was grown by Microphyt (Baillargues, France) in 5,000 L photobioreactor (PBR) consisting in $1.2 \mathrm{~km}$ of glass tubes with co-circulation of liquid medium and $\mathrm{CO}_{2}$ enriched air [40,41]. The PBR was set under a greenhouse in order to control temperature (between 22 and $28^{\circ} \mathrm{C}$ ) and the intensity of natural light using curtains. The $\mathrm{pH}$ set point of 7.5 was automatically controlled by $\mathrm{CO}_{2}$ injection and monitored by an inline Fermprobe F-235 pH probe from Broadley James (Silsoe, United Kingdom). Air was injected continuously at rate of $35 \mathrm{~L} / \mathrm{min}$. The culture medium used is a marine type medium, corresponding to a modified Hemerick's medium [42]. This medium was modified by addition of $\mathrm{N}$ and $\mathrm{P}$ up to 20 and $4 \mathrm{mmol} / \mathrm{L}$ respectively. Cultivation was conducted in semi-continuous conditions, thus maintaining the exponential growth phase during 85 days. Cells were harvested by bowl centrifugation at $6000 \mathrm{rpm}$ during $60 \mathrm{~min}$ at room temperature (maximum reachable temperature of $35^{\circ} \mathrm{C}$ ) using a $\mathrm{KG} 8006$ from GEA (Oelde, Germany) and concentrated at the rate of around 10-13\% dry weight. The biomass was frozen at $-20^{\circ} \mathrm{C}$ in polyethylene bags, heat sealed, and stored at $-20^{\circ} \mathrm{C}$. The biomass was then dispatched in aliquots in airtight glass bottles at $-18^{\circ} \mathrm{C}$ away from light. The total number of freezing / thawing cycles was 2 with freezing at $-18^{\circ} \mathrm{C}$ and thawing at room temperature.

\subsection{Materials}

$\mathrm{KH}_{2} \mathrm{PO}_{4}$ (CAS Number 7778-77-0), and $\mathrm{NaOH}$ (CAS Number 1310-73-2) were purchased from Sigma-Aldrich (Saint Louis, USA). Isolectin GS-IB 4 from Griffonia simplicifolia was purchased from Thermofischer Scientific, USA (Alexa Fluor ${ }^{\mathrm{TM}} 488$ Conjugate). Isolectin was used as fluorescence probe for labeled EPS. Water used in all experiments was deionised and obtained from an Elga Ionic system PURELAB Option. 


\subsection{Effect of pH and ionic strength}

P. cruentum biomass was resuspended at $0.2 \mathrm{~g}$ dry biomass / $100 \mathrm{~mL}$ in different buffers and let one hour under magnetic stirring at room temperature, away from direct light exposure. To investigate the influence of $\mathrm{pH}$, the different buffers used were $0.1 \mathrm{M} \mathrm{KH}_{2} \mathrm{PO}_{4}$ at $\mathrm{pH} 7,5$ and 8.5. For each of these buffers, a version with $1 \mathrm{M} \mathrm{NaCl}$ was made to investigate the influence of ionic strength. The $\mathrm{NaCl}$ content of the raw material being unknown, the final $\mathrm{NaCl}$ concentration of the samples might be higher. All suspensions were done in triplicate.

\subsection{Impact of three successive macerations with deionized water}

(1) The impact of successive macerations was assessed by resuspending $0.02 \mathrm{~g}$ dry biomass in $10 \mathrm{~mL}$ of deionized water during one hour under magnetic stirring, away from direct light exposure. All macerations were done in triplicate. One $\mathrm{mL}$ of this resuspension was withdrawn and used for CLSM.

(2) The suspension was then centrifuged at $2570 \mathrm{rpm}$ during 20 minutes at room temperature. The centrifuge was a 541/R with F45-30-11 rotor from Eppendorf (Hambourg, Germany). After centrifugation, the whole supernatant was harvested for further analysis whereas the pellet was resuspended in the same volume of distilled water as for the first resuspension $(10 \mathrm{~mL})$ and mixed using a vortex during two minutes. One $\mathrm{mL}$ of resuspension was withdrawn and used for microscopy.

(3) Step (2) was then repeated one more time.

\subsection{Characterization of supernatant}

\subsubsection{B-phycoerythrin content determination}

The absorbance spectrum between 220 and $800 \mathrm{~nm}$ was measured using a Monaco UVmc1 from Safas (Monaco) and semi-micro UV-cuvettes Brand (Wertheim, Germany). Extract 
samples were diluted by 4 with the appropriate buffer to respect the Beer-Lambert law and each modality was measured in triplicate.

The quantification of B-phycoerythrin (B-PE) in aqueous extracts was calculated using the following equations firstly used by Bermejo et al. (2002) [1]:

$[\mathrm{R}-$ phycocyanin $(\mathrm{R}-\mathrm{PC})](\mathrm{mg} / \mathrm{mL})=(\mathrm{OD} 620-0.7 * \mathrm{OD} 650) / 7.38$

(Equation 1)

[Allophycocyanin $($ APC $)](\mathrm{mg} / \mathrm{mL})=($ OD650-0.19*OD620) $) / 5.65$

(Equation 2)

[B-phycoerythrin] $(\mathrm{mg} / \mathrm{mL})=(\mathrm{OD} 565-2.8 *[\mathrm{R}-\mathrm{PC}]-1.34 *[\mathrm{APC}]) / 12.7 \quad($ Equation 3$)$

OD620, OD650, and OD565 correspond to the optical densities measured respectively at 620 $\mathrm{nm}, 650 \mathrm{~nm}$ and $565 \mathrm{~nm}$.

A purity index can also be calculated through the OD545/OD280 ratio. The extract is considered to have a high purity level beyond a value of 4 [43].

The B-PE content was determined in $\mathrm{mg} / \mathrm{mL}$ and was then converted in $\mathrm{mg} / \mathrm{g}$ dry biomass.

\subsection{2. $\mathrm{pH}$ determination}

The $\mathrm{pH}$ was measured using a HI 2209 pH meter from Hanna instruments (Lingolsheim, France) and a DJ133 pH probe from VWR (Radnor, USA). The device was calibrated using reference buffer solution. The result corresponds to the value stable after 10 seconds during measurement.

\subsection{High pressure homogenizer}

P. cruentum biomass was resuspended at the rate of $1.5 \mathrm{~g}$ dry biomass / $100 \mathrm{~mL}$ of deionized water overnight at $5^{\circ} \mathrm{C}$, away from direct light exposure and under magnetic stirring. This resuspension was treated by a Microfluidizer LM10 high pressure homogenizer from 
Microfluidics (Westwood, USA). Ice was used to cool down the system in order to avoid protein denaturation. The different treatments involved a one shot treatment at $70 \mathrm{MPa}$ and a two-steps treatment at $70 \mathrm{MPa}$ and $120 \mathrm{MPa}$.

\subsection{Confocal fluorescence microscope}

Transmission and fluorescence images of P. cruentum resuspensions were captured on a Nikon C1Si Eclipse TE 2000 U confocal microscope (Nikon, Japan). Imaging was carried out with a $\times 100$ PlanApo objective (NA: 1.4, oil, Nikon, Japan). The $561 \mathrm{~nm}$ laser diode was chosen depending on: (i) the maximum excitation wavelength of B-PE at $545 \mathrm{~nm}$ and (ii) the maximum excitation wavelength of isolectin at $488 \mathrm{~nm}$. The fluorescence probe was added to the sample at the rate of $40 \mu \mathrm{L} / \mathrm{mL}$ of resuspension sample. Fluorescence properties of phycobiliproteins and chlorophyll from $P$. cruentum have been well studied [8,44-47]. Table 1 describes the wavelength range chosen for the detection of fluorescent substances of interest. The fluorescence emission signal was collected on C1Si multispectral detector with a spectral resolution of $8 \mathrm{~nm}$. Wolf and Schüssler [36] reported the normalized fluorescence emission spectra from phycobiliproteins and chlorophyll. It is worth noting, that the fluorescence emission peaks of phycocyanin, allophycocyanin and chlorophyll overlap between 625 and $725 \mathrm{~nm}$, meaning that the channels associated with phycocyanin and chlorophyll quantitatively over estimate phycocyanin and chlorophyll fluorescence emission respectively. This is not the case for B-PE. The choice was made to not investigate allophycocyanin, because of the strong overlapping of fluorescence emission peaks.

Five $\mu \mathrm{L}$ of resuspension were mounted between slid and slip cover. Calibration of detected fluorescence regarding B-PE concentration for a given laser power was made by acquisition of distilled water (blank) and different dilutions of P. cruentum extract (cell-free supernatants from resuspension). The fluorescence signal varied proportionally to the dilution rate (data 
not shown). The distilled water sample did not show any fluorescence emission higher than noise signal background (data not shown). The two used fluorescence probes were tested individually and together with all lasers to determine false positive fluorescence emission (possibly from autofluorescence of $P$. cruentum). It was observed that the chloroplast very slightly emitted fluorescence between 495 and $515 \mathrm{~nm}$ using the $488 \mathrm{~nm}$ laser without using isolectin (data not shown). Besides that, no interference or false positive were detected.

\subsection{Statistical treatment}

The statistical treatment was processed by XLStat v.14.0. by Addinsoft (Paris, France). Analysis of variance (ANOVA) was performed to determine significant differences between the samples for a given parameter. Significance was established at $\mathrm{p}<0.05$. ANOVA showing significant differences lead to the use of Newman-Keuls pair test.

\section{Results and discussion}

\subsection{Confocal fluorescence microscopy image description}

The observation in transmitted light picture of resuspension of P. cruentum (Figure 1A) showed round cells with inhomogeneous content delimited by a membrane that appeared as a white line. The whole system seemed to be kept together by an extracellular matrix, but it was hardly visible because it appeared translucent on the picture. The presence of such matrix was perceived during microscopic observation because of the coordinated motion of the cells. The blurry cells and white spots resulted from cells outside the focal plane of the objective. When looking at the merged image of transmitted light and fluorescence emission of all channels selected for this study (channels 1, 2 and 3 (Figure 1B)), fluorescence was detected in three areas: intracellular area, extracellular area, and spherical objects of about $2 \mu \mathrm{m}$ diameter with high fluorescence emission intensity in extra and intracellular areas. In this study, these 
objects will be named vesicles for more convenience. They were already observed in previous work [35].

Intracellular fluorescence was observed in channels 1, 2 and 3 (Figure 1C, 1D and 1E) and could be attributed to the phycobiliproteins (B-PE and R-phycocyanin (R-PC)) and chlorophyll, which is consistent with what is described in the literature $[44,48]$. On the fluorescence emission pictures (Figure 1B, 1C and 1D), the chloroplast appeared as a fluorescent rounded shaped object with bright spots which are likely attributable to phycobilisomes. The intracellular fluorescence emission area was clearly separated from the extracellular fluorescence emission by a black area corresponding to the surface of the cell by comparison with transmitted light picture (Figure 1B). This excluding space around the cells was larger than the space delimited by the membrane (by comparison with transmitted light picture, Figure 1A) and so, can be attributed to $P$. cruentum's well-known bound exopolysaccharide sheath [6].

The extracellular fluorescence indicates the presence of phycobiliproteins (Figure 1B, 1C and 1D) and, at a much lesser extent, of chlorophyll (Figure 1E), that were both released outside of the cells. These extracellular B-PE and R-PC fluorescence emissions are uniformly distributed. On the opposite, the vesicles showed a distinct round shape, with sometimes a "capsule-like" aspect conveyed by the weaker fluorescence emission intensity in the middle (Figure 1B, 1C and 1D). It is unclear if chlorophyll was also part of this structure (Figure 1E). On the other hand, the vesicles might actually have included allophycocyanin since the other two phycobiliproteins B-PE and R-PC were clearly present (Figure 1C and 1D). The presence of chlorophyll, which is a hydrophobic compound in the aqueous phases such as the extracellular space, could be explained by protein-chlorophyll complexes naturally occurring in P.cruentum's photosynthetic membranes [48] and so opens the possibility for proteinprotein associations. 
The addition of isolectin allowed the marking of the bound exopolysaccharide matrix but not that of the sheath, which stayed visible from its lack of fluorescence (Figure 2A). The probe interacted strongly with the bound EPS resulting in the change of aspect of the extracellular matrix, which was different from the native aspect of the sample without isolectin. Indeed while the extracellular matrix appeared translucent without the addition of isolectin (Figure 1A), it seemed to be solidified due to the marking and appeared clearly surrounding the cells on the transmitted light picture (Figure 2B). Therefore, both samples, with and without isolectin are important to consider. Regarding the channels attributed to phycobiliproteins and

to chlorophyll, no important change was seen compared to the sample without the addition of isolectin (Figure 2C, 2D and 2E versus Figure 1C, 1D and 1E). According to Figures 2C, 2D and 2E, the extracellular matrix, corresponding to the bound EPS matrix, was wrapped around cells and vesicles, keeping the whole structure together. Also, vesicles happened to be lightly marked by isolectin as well, suggesting that EPS were involved in the vesicle composition (Figure 2C, 2D and 2E). It is plain to imagine that this extracellular matrix can prevent the extraction of B-PE and other compounds by protecting the cells and possibly hold back substances, by physical entrapment or by involving molecular interactions.

\subsection{Effect of $\mathrm{pH}$ and ionic strength variations on the stability of vesicles}

We hypothesize that this aggregation of phycobiliproteins and chlorophyll could result from an association of proteins with the EPS. This kind of association between these two families of molecules and the spherical "capsule-like" aspect of these objects could point to identify them as coacervates $[49,50]$. Coacervation is defined as the separation between two liquid phases in colloidal systems [51] leading to a concentrated colloid phase called "coacervate" and a less concentrated phase being the equilibrium phase. In practice, the coacervate can be solid-like with high viscosity and can be seen as a precipitate [29]. The association occurring 
is driven by electrostatic interactions and the main parameters influencing the stability of coacervates are $\mathrm{pH}$ and ionic strength, acting respectively on the charges of compounds and on entropy [29,52]. Regarding sulfated polysaccharides, including microbial exopolysaccharides, the stability of the precipitates is framed by narrow physicochemical conditions. Optimal conditions appear to be a $\mathrm{pH}$ value close to the isoelectric point of protein and $\mathrm{NaCl}$ concentration below $0.1 \mathrm{M}[25,27,32]$. For that reason, in this study, the biomass was resuspended in deionized water and in $0.1 \mathrm{M}$ phosphate buffer with different $\mathrm{pH}$ values: 5, 7 and 8.5. The $\mathrm{pH}$ values of 5 and 8.5 are close to the fluorescence stability limits of B-PE [53]. It is noteworthy to mention that the isoelectric point of phycoerythrin ranges between 4.5 and 5.1 depending on what specie it was isolated from [54]. Also, for each pH value, $1 \mathrm{M}$ of $\mathrm{NaCl}$ was added to the buffer to be in high ionic strength conditions.

For better readability, CLSM pictures presented in Figures 3, 4 and 5 were generated by merging channel 1 (B-PE, yellow), channel 3 (chlorophyll, red), and channel 4 (isolectin, green) when appropriate. B-PE was rather ubiquitous in all the samples. Chlorophyll typically was found in the chloroplast of the cell, and isolectin was meant to label the EPS. By comparing channel 1 and 2 (data not shown), it could be stated that R-PC was associated with the presence of B-PE, so we hypothesized that so was also allophycocyanin. Given the poor amount of R-PC and allophycocyanin compared to B-phycoerythrin in P. cruentum, it was chosen to keep only channel 1 to mark the presence of the phycobiliproteins.

When performing ANOVA on the samples based on water and phosphate buffer with or without $\mathrm{NaCl}$, significant differences of $\mathrm{B}-\mathrm{PE}$ content and purity index values were found (Table 2, $\mathrm{p}=0.003$ and $\mathrm{p}<0.0001$ respectively). However, in the case of the samples based on water and the samples based on $\mathrm{pH} 7$ phosphate buffer without addition of $\mathrm{NaCl}$, the $\mathrm{B}-\mathrm{PE}$ contents and purity indexes of the supernatants were not significantly different. Likewise, the 
visual observations made by CLSM of those resuspensions were similar (Figure 3). The use of water or $\mathrm{pH} 70.1 \mathrm{M}$ phosphate buffer seemed to be equivalent from the perspective of the studied parameters.

In phosphate buffer with and without $\mathrm{NaCl}, \mathrm{B}-\mathrm{PE}$ content and purity index of the samples supernatants were significantly lower at $\mathrm{pH} 5$ without $\mathrm{NaCl}$ and $\mathrm{pH} 8.5$ with and without $\mathrm{NaCl}$ compared to the $\mathrm{pH} 7$ supernatants with and without $\mathrm{NaCl}$ (Table 2). This suggests that $\mathrm{pH}$ variations had a stronger impact on the extracellular B-PE content than the addition of $\mathrm{NaCl}$. When looking at the CLSM images, the only visible change was a more "packed" aspect of the vesicles at $\mathrm{pH} 8.5$ without $\mathrm{NaCl}$ (Figure 3). Nevertheless, this phenomenon did not occur at $\mathrm{pH} 8.5$ with the addition of $\mathrm{NaCl}$. It can be hypothesize that the interactions induced by higher $\mathrm{pH}$ leading to the aggregation of the vesicles were suppressed by the higher ionic strength induced by the addition of $\mathrm{NaCl}$.

The fact that vesicles were still present with addition of $\mathrm{NaCl}$ is surprising because, in theory, the increase of the ionic strength induced by the addition of $\mathrm{NaCl}$ should suppress electrostatic interactions and thus prevent complex formation between molecules [50,55]. In conclusion for this group of samples, the major change was seen at $\mathrm{pH} 8.5$ without $\mathrm{NaCl}$ addition with an agglomeration of the vesicles. This suggests that the interactions between the compounds involved in these structures (presumably phycobiliprotein and EPS) were strengthened. Also, the addition of $1 \mathrm{M} \mathrm{NaCl}$ could prevent the agglomeration of vesicles at pH8.5 but could not visibly dissociate the vesicles at any $\mathrm{pH}$ value. This is contradictory with the theory built around coacervates that states that interactions leading to coacervation and complex formation are strengthened at lower $\mathrm{pH}$, closer to the isoelectric point of protein and at moderate ionic strength $[25,27,32]$. The vesicles should then likely be categorized as precipitates. 
With the isolectin dyeing (Figure 4), the extracellular matrix appeared clearly although its aspect was different in phosphate buffer compared to in water, regardless of the $\mathrm{pH}$ or $\mathrm{NaCl}$ addition. The $\mathrm{pH}$ variations and addition of $\mathrm{NaCl}$ in phosphate buffer did not seem to impact the cohesion of the extracellular matrix. However, the disappearance of extracellular B-PE fluorescence in sample made of phosphate buffer compared to the sample without isolectin could suggest an adsorption of B-PE by isolectin and thus the existence of protein / protein interactions in those specific conditions (Figure 4). Since this was not the case in the sample in water, this phenomenon could be induced by the higher ionic strength or the presence of ions present in the buffer and could lead to a bias in the observation. However, in all samples including the one made in water, there was a clear juxtaposition of B-PE fluorescence emission with the isolectin marked extracellular matrix, suggesting a trapping of the protein in the matrix network.

To conclude, $\mathrm{pH}$ had the strongest impact on the resuspensions in terms of B-PE content in supernatants and organization of the vesicles. Ionic strength variations might play a less impactful role on the interactions between the vesicles, but higher ionic strengths could not manage to meaningfully alter the structure of the vesicles. Moreover, the resuspension in water showed the same B-PE concentration and purity index in the supernatant than the sample obtained with phosphate buffer at $\mathrm{pH} 7$ and showed the highest B-PE content in supernatants. Resuspension in deionized water was chosen for the next experiments.

\subsection{Effect of extraction processes on the stability of vesicles}

\subsubsection{Successive macerations}

The successive macerations lowered significantly the extracellular B-PE content at each step as shown in Figure 5 and Table $2(\mathrm{p}<0.0001)$. The abundance and fluorescence emission 
intensity of vesicles also decreased but some of them were still present after three macerations steps. Most of the B-PE was extracted during the first step ( $85 \mathrm{mg} / \mathrm{g}$ dry biomass). At the second step, only a very small quantity of the previous amount ( $8 \mathrm{mg} / \mathrm{g}$ dry biomass) was extracted. The third step allowed the extraction of a significantly lower amount of B-PE (Table 2). Also, the purity index significantly dropped at each step along the B-PE concentration $(\mathrm{p}<0.0001)$. The same observation could be made for the $\mathrm{pH}$ value that did not decrease further than $6.7(\mathrm{p}=0.0016)($ Table 2$)$.

Through the isolectin dyeing, a decrease of the extracellular matrix occurrence leading to the scattering of $P$. cruentum cells without their enveloping matrix was observed with the increase of macerations steps (Figure 5). After the third resuspension step, few vesicles were still visible between the cells and showed fluorescence emission from B-PE and isolectin (Figure 5). That means that extracellular B-PE bound to EPS was still present in the sample and this highlights the important role that bound EPS plays as an obstacle in the extraction of this protein from $P$. cruentum.

\subsubsection{High pressure homogenizer treatment}

Figure 6 shows the results obtained after HPH treatment. The untreated control sample is shown in Figure 6A. Both one-step (Figure 6B) and two-steps treatments (Figure 6C) had similar profiles. While some cells remained whole, a lot of fluorescence-less crescent-looking objects were visible, resulting from shear forces destructing the cells and ripping off bits of the sheath that appear as fluorescence-less crescents. Debris with higher fluorescence emission was also visible (Figures 6B and 6C). The treatment by HPH dissociated the extracellular matrix through the application of shear forces, scattering extracellular matrix bits and cells (Figure 6D). With the isolectin dyeing, debris could be identified as bits of bound EPS matrix, and so did chloroplasts, identified by their intense B-PE and chlorophyll 
fluorescence (Figure 6D). Besides this, very rare vesicles present in the control (Figure 6A) were seen after one step treatment (Figure 6B) and no vesicles were observed in two-steps treatments (Figure 6D). This observation confirmed the efficiency of the HPH treatment regarding the disruption of cells and extracellular matrix, both representing the biggest obstacles to the extraction of B-PE from P. cruentum. This is consistent with previous reported studies that were made at molecular scale. In fact, some studies [56-58] showed that HPH treatment reduced molecular weight of polysaccharides, thus limiting viscosity.

Surprisingly, there was no significant extraction of B-PE after one-step treatment but only after two-steps treatments where B-PE concentration significantly decreased $(\mathrm{p}=0.0115$, Table 2). The reasons could be a protein denaturation caused by the high pressure, the elevation of temperature in the system, or both. The purity index significantly dropped after both treatments, but this drop was not significantly different whether the one-step or two-step treatment was applied $(\mathrm{p}<0.0046)$ (table 2). This suggests that the $70 \mathrm{MPa}$ high pressure treatment could extract other intracellular compounds by disrupting the cells, but that the second step at $120 \mathrm{MPa}$ did not make any further effect besides denaturing B-PE.

\section{Conclusion}

Benefits of this study are numerous: development of labeling method for the observation of EPS in microalgae, understanding of protein-EPS interactions in situ, impact of some mechanical extractions on these interactions, and, regarding the application purpose, the importance of the bound EPS for extraction yields.

The experiments combining confocal laser scanning microscopy with fluorescent isolectin probe showed that the observed fluorescent objects consisted of an association of 
phycobiliproteins (mainly B-PE) and EPS. Their stability towards $\mathrm{pH}$ and ionic strength variations arouses interests since the understanding of this system could help building more stable protein / polysaccharide complexes. The observed fluorescent vesicles do not fit in the theoretical behavior of coacervates and may rather be stable precipitates.

Still, this experiment was made in the context of a complex environment and some uncontrolled parameters such as the presence of endogenous ions or other proteins could play a role in the stability of the vesicles. Further understanding of the molecular interactions involved between B-PE and EPS of P. cruentum could be investigated by working in model conditions, using purified protein and EPS.

Also, this study highlights for the first time in detail the importance of bound EPS matrix towards the extraction of target compounds (such as B-PE) as an obstacle in the case of P. cruentum biomass: this extracellular matrix, encapsulating the cells and the smaller vesicles, acts as a shelter against disruption processes and is likely to trap target compounds both by physical entrapment and through molecular interactions. Successive macerations with water or HPH treatment are efficient methods to free the P. cruentum cells and B-PE from the bound EPS matrix. However, maceration is a simple method and provides the extract with the greatest amount of BPE and the best purity index within our experimental conditions.

Another way to improve extraction could be to frame appropriate cultural conditions and growth phase in order to harvest microalgae with limited amount of bound EPS.

\begin{abstract}
:
During the extraction processes of B-phycoerythrin from P. cruentum, the possibility of the occurrence of extraction-inhibiting B-phycoerythrin / exopolysaccharide (EPS) complexes was highlighted. The use of confocal laser scanning microscopy allowed the observation of
\end{abstract}


the cells including their sheath and their chloroplast, the bound EPS matrix, and extracellular vesicles involving phycobiliproteins and EPS in P. cruentum biomass resuspensions. The observations were performed using autofluorescence and fluorescence marking.

$\mathrm{pH}$ variations showed more impact than ionic strength increase induced by $\mathrm{NaCl}$ addition on the B-phycoerythrin content and the organization of vesicles. Namely, agglomeration of the vesicles could be observed at $\mathrm{pH} 8.5$ without $\mathrm{NaCl}$ addition. With addition of $1 \mathrm{M} \mathrm{NaCl}$, this phenomenon was prevented but the vesicles were not visibly dissociated for any $\mathrm{pH}$ value. These results point towards a precipitate rather than a coacervate, which are expected to have narrow stability conditions regarding $\mathrm{pH}$ and ionic strength.

In an attempt to dissolve or break the vesicles and the extracellular matrix, successive macerations in water and use of high pressure homogenizer process in one-step or two-step treatments were applied to the resuspensions. The successive macerations could free the cells and the vesicles from the extracellular matrix, whereas the homogenizer treatment disrupted the extracellular matrix, the vesicle and a part of the cells. In our case, only the successive macerations showed a positive extraction since the high pressure treatment caused unwanted denaturation.

It is concluded that more experiments in model conditions could help understand the nature of the interactions between phycobiliproteins and EPS leading to the formation of the vesicles.

Porphyridium cruentum, confocal fluorescence microscopy, complexation, B-phycoerythrin, exopolysaccharide.

\section{Graphical abstract}




\section{Schematic representation of \\ Porphyridium cruentum biomass resuspension \\ observed by confocal microscopy}



Fluorescence emission channels

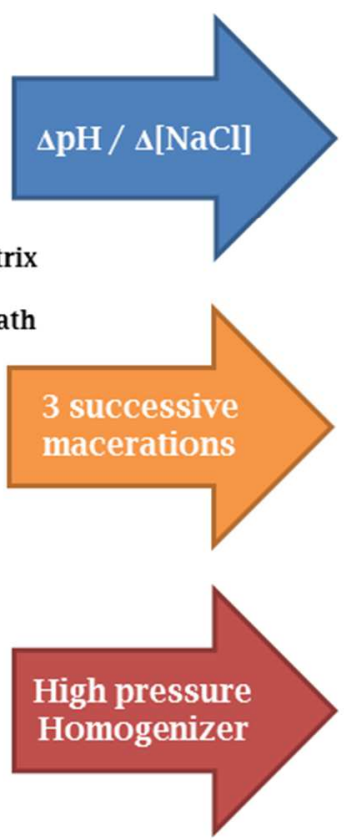

Bound EPS matrix,

vesicles and cells disruption

\section{Highlights}

- P. cruentum chloroplast and EPS were labelled and observed by confocal microscopy.

- Phycobiliproteins/EPS vesicles were identified.

- Vesicles were found stable towards $\mathrm{pH}$ and ionic strength.

- EPS inhibited the extraction of B-phycoerythrin.

\section{Acknowledgement}

This work was supported by the Regional Council of Bourgogne - Franche Comté and the "Fonds Européens de Développement Régional" (FEDER) for the "PARI Alim+" project.

\section{Declaration of authors contributions}


Camille Loupiac, Nathalie Cayot, Céline Lafarge and Thierry Tran designed the experiment. Thierry Tran and Céline Lafarge carried out the experiment, acquired, processed and interpreted the data. Pascale Winckler provided access and assistance to the use of confocal microscopy. Rémi Pradelles provided the microalgal biomass. Thierry Tran took the lead in writing the manuscript but all authors provided critical feedbacks and helped shape the research, analysis and manuscript.

\section{Conflict of interest statement}

The authors confirm that there are no known conflicts of interest associated with this publication and there has been no significant financial support for this work that could have influenced its outcome.

\section{Statement of Informed Consent, Human/Animal Rights}

No conflicts, informed consent, human or animal rights are applicable for this work.

\section{Declaration of authors agreement to authorship and submission of the manuscript for peer review.}

The authors declare that this manuscript is original, has not been published before and is not currently being considered for publication elsewhere. We confirm that the manuscript has been read and approved by all named authors and that there are no other persons who satisfied the criteria for authorship. We further confirm that the order of authors listed in the manuscript has been approved by all of us. The Corresponding Author is the sole contact for the Editorial process. She is responsible for communicating with the other authors about progress, submissions of revisions and final approval of proofs. Signed by all authors as 
follows: Thierry Tran, Céline Lafarge, Pascale Winckler, Rémi Pradelles, Nathalie Cayot,

Camille Loupiac.

\section{References}

[1] R. Bermejo, J.M. Alvarez-Pez, F.G. Acien Fernandez, E. Molina Grima, Recovery of pure B-phycoerythrin from the microalga Porphyridium cruentum, J. Biotechnol. (2002) 73-85.

[2] R. Bermejo, E. Ruiz, F.G. Acien, Recovery of B-phycoerythrin using expanded bed adsorption chromatography: Scale-up of the process, Enzyme Microb. Technol. 40 (2007) 927-933.

[3] J. Benavides, M. Ritopalomares, Simplified two-stage method to B-phycoerythrin recovery from Porphyridium cruentum, J. Chromatogr. B. 844 (2006) 39-44.

[4] A.N. Glazer, Phycobiliproteins-a family of valuable, widely used fluorophores, J. Appl. Phycol. 6 (1994) 105-112.

[5] R.F. Jones, H.L. Speer, W. Kury, Studies on the growth of the red alga Porphyridium cruentum, Physiol. Plant. 16 (1963) 636-643.

[6] E. Gantt, S.F. Conti, The ultrastructure of Porphyridium cruentum, J. Cell Biol. 26 (1965) 365-381.

[7] M. Brody, A.E. Vatter, Observations on cellular structures of Porphyridium cruentum, J. Cell Biol. 5 (1959) 289-294.

[8] C.S. French, J.H. Smith, H.I. Virgin, R.L. Airth, Fluorescence-Spectrum Curves of Chlorophylls, Pheophytins, Phycoerythrins, Phycocyanins and Hypericin., Plant Physiol. 31 (1956) 369.

[9] E. Gantt, C.A. Lipschultz, B. Zilinskas, Further evidence for a phycobilisome model from selective dissociation, fluorescence emission, immunoprecipitation, and electron microscopy, Biochim. Biophys. Acta BBA-Bioenerg. 430 (1976) 375-388.

[10] E. Gantt, C.A. Lipschultz, Phycobilisomes of Porphyridium cruentum, J. Cell Biol. 54 (1972) 313-324.

[11] A.N. Glazer, Phycobilisomes: structure and dynamics, Annu. Rev. Microbiol. 36 (1982) $173-198$.

[12] M.R. Fuentes, J.G. Sánchez, J.F. Sevilla, F.A. Fernández, J.S. Pérez, E.M. Grima, Outdoor continuous culture of Porphyridium cruentum in a tubular photobioreactor: quantitative analysis of the daily cyclic variation of culture parameters, J. Biotechnol. 70 (1999) 271-288.

[13] J. Ramus, D.M. Robins, The correlation of Golgi activity and polysaccharide secretion in Porphyridium, J. Phycol. 11 (1975) 70-74.

[14] S. Geresh, I. Adin, E. Yarmolinsky, M. Karpasas, Characterization of the extracellular polysaccharide of Porphyridium sp.: molecular weight determination and rheological properties, Carbohydr. Polym. 50 (2002) 183-189.

[15] S. Geresh, N. Lupescu, S. Arad, Fractionation and partial characterization of the sulphated polysaccharide of Porphyridium cruentum, Phytochemistry. 31 (1992) 41814186.

[16] S. (Malis) Arad, O. Levy-Ontman, Red microalgal cell-wall polysaccharides: biotechnological aspects, Curr. Opin. Biotechnol. 21 (2010) 358-364.

[17] R.F. Jones, Extracellular mucilage of the red alga Porphyridium cruentum: Mucilage of Porphyridium, J. Cell. Comp. Physiol. 60 (1962) 61-64. 
[18] A.K. Patel, C. Laroche, A. Marcati, A.V. Ursu, S. Jubeau, L. Marchal, E. Petit, G. Djelveh, P. Michaud, Separation and fractionation of exopolysaccharides from Porphyridium cruentum, Bioresour. Technol. 145 (2013) 345-350.

[19] J. Heaney-Kieras, L. Rodent, D.J. Chapman, The Covalent Linkage of Protein to Carbohydrate in the Extraceliular Protein- Polysaccharide from the Red Alga Porphyridium cruentum, 165 (1977) 9.

[20] N. Soanen, E. Da Silva, C. Gardarin, P. Michaud, C. Laroche, Improvement of exopolysaccharide production by Porphyridium marinum, Bioresour. Technol. 213 (2016) 231-238.

[21] M.F. de J. Raposo, A.M.M.B. de Morais, R.M.S.C. de Morais, Influence of sulphate on the composition and antibacterial and antiviral properties of the exopolysaccharide from Porphyridium cruentum, Life Sci. 101 (2014) 56-63.

[22] M. Adda, J.C. Merchuk, S.M. Arad, Effect of nitrate on growth and production of cellwall polysaccharide by the unicellular red alga Porphyridium, Biomass. 10 (1986) 131140.

[23] T.M.M. Bernaerts, C. Kyomugasho, N. Van Looveren, L. Gheysen, I. Foubert, M.E. Hendrickx, A.M. Van Loey, Molecular and rheological characterization of different cell wall fractions of Porphyridium cruentum, Carbohydr. Polym. 195 (2018) 542-550.

[24] S. Jubeau, L. Marchal, J. Pruvost, P. Jaouen, J. Legrand, J. Fleurence, High pressure disruption: a two-step treatment for selective extraction of intracellular components from the microalga Porphyridium cruentum, J. Appl. Phycol. 25 (2013) 983-989.

[25] V. Galazka, D. Smith, D. Ledward, E. Dickinson, Interactions of ovalbumin with sulphated polysaccharides: effects of $\mathrm{pH}$, ionic strength, heat and high pressure treatment, Food Hydrocoll. 13 (1999) 81-88.

[26] B. Mulloy, The specificity of interactions between proteins and sulfated polysaccharides, An. Acad. Bras. Ciênc. 77 (2005) 651-664.

[27] V.B. Galazka, D. Smith, D.A. Ledward, E. Dickinson, Complexes of bovine serum albumin with sulphated polysaccharides: effects of $\mathrm{pH}$, ionic strength and high pressure treatment, Food Chem. 64 (1999) 303-310.

[28] V.B. Galazka, I.G. Sumner, D.A. Ledward, Changes in protein-protein and proteinpolysaccharide interactions induced by high pressure, Food Chem. 57 (1996) 393-398.

[29] C.G. de Kruif, F. Weinbreck, R. de Vries, Complex coacervation of proteins and anionic polysaccharides, Curr. Opin. Colloid Interface Sci. 9 (2004) 340-349.

[30] C. de Kruif, R. Tuinier, Polysaccharide protein interactions, Food Hydrocoll. 15 (2001) $555-563$.

[31] A.N. Gurov, N.V. Gurova, A.L. Leontiev, V.B. Tolstoguzov, Equilibrium and nonequilibrium complexes between bovine serum albumin and dextran sulfate-I. Complexing conditions and composition of non-equilibrium complexes, Food Hydrocoll. 2 (1988) 267-283.

[32] F. Weinbreck, H. Nieuwenhuijse, G.W. Robijn, C.G. de Kruif, Complexation of Whey Proteins with Carrageenan, J. Agric. Food Chem. 52 (2004) 3550-3555.

[33] Z. Tang, Jilu zhao, B. Ju, W. Li, S. Wen, Y. Pu, S. Qin, One-step chromatographic procedure for purification of B-phycoerythrin from Porphyridium cruentum, Protein Expr. Purif. 123 (2016) 70-74.

[34] A. Marcati, A.V. Ursu, C. Laroche, N. Soanen, L. Marchal, S. Jubeau, G. Djelveh, P. Michaud, Extraction and fractionation of polysaccharides and B-phycoerythrin from the microalga Porphyridium cruentum by membrane technology, Algal Res. 5 (2014) 258263.

[35] T. Tran, E. Denimal, C. Lafarge, L. Journaux, J.A. Lee, P. Winckler, J.-M. PerrierCornet, R. Pradelles, C. Loupiac, N. Cayot, Effect of high hydrostatic pressure on 
extraction of B-phycoerythrin from Porphyridium cruentum: Use of confocal microscopy and image processing, Algal Res. 38 (2019) 101394.

[36] E. Wolf, A. Schübler, Phycobiliprotein fluorescence of Nostoc punctiforme changes during the life cycle and chromatic adaptation: characterization by spectral confocal laser scanning microscopy and spectral unmixing, Plant Cell Environ. 28 (2005) 480491.

[37] R.H. Webb, Confocal optical microscopy, Rep. Prog. Phys. 59 (1996) 427-471.

[38] T. Norton, R. Thompson, J. Pope, C. Veltkamp, B. Banks, C. Howard, S. Hawkins, Using confocal laser scanning microscopy, scanning electron microscopy and phase contrast light microscopy to examine marine biofilms, Aquat. Microb. Ecol. 16 (1998) 199-204.

[39] T. Zimmermann, J. Rietdorf, R. Pepperkok, Spectral imaging and its applications in live cell microscopy, FEBS Lett. 546 (2003) 87-92.

[40] A. Muller-Feuga, M. Lemar, E. Vermel, R. Pradelles, L. Rimbaud, P. Valiorgue, Appraisal of a horizontal two-phase flow photobioreactor for industrial production of delicate microalgae species, J. Appl. Phycol. 24 (2012) 349-355.

[41] A. Muller-Feuga, Réacteur photosynthétique pour la culture de microorganismes et procédé de culture de microorganismes, WO2010109108 A1, 2010.

[42] G. Hemerick, Culture methods and growth measurements. In:Stein JR (ed). Handbook of physiological methods, Cambridge University Press, Cambridge, 1973.

[43] A. Camara-Artigas, J. Bacarizo, M. Andujar-Sanchez, E. Ortiz-Salmeron, C. MesaValle, C. Cuadri, J.M. Martin-Garcia, S. Martinez-Rodriguez, T. Mazzuca-Sobczuk, M.J. Ibañez, J.P. Allen, pH-dependent structural conformations of B-phycoerythrin from Porphyridium cruentum, FEBS J. 279 (2012) 3680-3691.

[44] E. Gantt, C.A. Lipschultz, Phycobilisomes of Porphyridium cruentum. Pigment analysis, Biochemistry. 13 (1974) 2960-2966.

[45] N. Murata, M. Nishimura, T. Atusi, Fluorescence of Chlorophyll in Photosynthetic Systems, Biochim Biophys Acta. 126 (1966) 234-243.

[46] N. Murata, I. Light-Induced Change of Chlorophyll a Fluorescence in Porphyridium cruentum, Biochim Biophys Acta. 162 (1968) 242-251.

[47] S.S. Brody, M. Brody, Action Spectra for Sensitization of Ligth Emission from Monomeric and Aggregated Chlorophyll at Physiological and Liquid Nitrogen Temperatures, Arch. Biochem. Biophys. 95 (1961) 521-525.

[48] T. Redlinger, E. Gantt, Photosynthetic Membranes of Porphyridium cruentum: An Analysis of Chlorophyll-Protein Complexes and Heme-Binding Proteins, Plant Physiol. 73 (1983) 36-40.

[49] C. Sanchez, D. Renard, Stability and structure of protein-polysaccharide coacervates in the presence of protein aggregates, Int. J. Pharm. 242 (2002) 319-324.

[50] S.L. Turgeon, M. Beaulieu, C. Schmitt, C. Sanchez, Protein-polysaccharide interactions: phase-ordering kinetics, thermodynamic and structural aspects, Curr. Opin. Colloid Interface Sci. (2003) 14.

[51] IUPAC compendium of Chemical Technology, (1997).

[52] S.L. Turgeon, C. Schmitt, C. Sanchez, Protein-polysaccharide complexes and coacervates, Curr. Opin. Colloid Interface Sci. 12 (2007) 166-178.

[53] M. Munier, S. Jubeau, A. Wijaya, M. Morançais, J. Dumay, L. Marchal, P. Jaouen, J. Fleurence, Physicochemical factors affecting the stability of two pigments: Rphycoerythrin of Grateloupia turuturu and B-phycoerythrin of Porphyridium cruentum, Food Chem. 150 (2014) 400-407.

[54] B.A. Bryant, Phycoerythrocyanin and Phycoerythrin: Properties and Occurrence in Cyanobacteria, J. Gen. Microbiol. 128 (1981) 835-844. 
[55] F. Weinbreck, H. Nieuwenhuijse, G.W. Robijn, C.G. de Kruif, Complex Formation of Whey Proteins: Exocellular Polysaccharide EPS B40, Langmuir. 19 (2003) 9404-9410.

[56] A. Villay, F. Lakkis de Filippis, L. Picton, D. Le Cerf, C. Vial, P. Michaud, Comparison of polysaccharide degradations by dynamic high-pressure homogenization, Food Hydrocoll. 27 (2012) 278-286.

[57] R. Ye, F. Harte, High pressure homogenization to improve the stability of caseinhydroxypropyl cellulose aqueous systems, Food Hydrocoll. 35 (2014) 670-677.

[58] P. Paquin, Technological properties of high pressure homogenizers: the effect of fat globules, milk proteins, and polysaccharides, Int. Dairy J. (1999) 7.

[59] L.A. Murphy, I.J. Goldstein, Five alpha-D-galactopyranosyl-binding isolectins from Bandeiraea simplicifolia seeds., J. Biol. Chem. 252 (1977) 4739-4742. 
Figure captions

Figure 1: Fluorescence emission images obtained by CLSM from P.cruentum resuspension at $0.2 \mathrm{~g}$ dry biomass / $100 \mathrm{~mL}$ in deionized water: (A) transmitted light image, (B) merged image of transmitted light image with channels 1, 2 and 3, (C) channel 1 attributed to fluorescence emission of B-phycoerythrin, (D) channel 2 attributed to fluorescence emission of R-phycocyanin, (E) channel 3 attributed to fluorescence emission of chlorophyll. The bar corresponds to a length of $10 \mu \mathrm{m}$.

Figure 2: Fluorescence emission images obtained by CLSM from P.cruentum resuspension at $0.2 \mathrm{~g}$ dry biomass / $100 \mathrm{~mL}$ deionized water with the addition of isolectin fluorescence probe: (A) channel 4 attributed to isolectin, (B) transmitted light image, (C) channel 1 attributed to fluorescence emission of B-phycoerythrin, (D) channel 2 attributed to fluorescence emission of R-phycocyanin and (E) channel 3 attributed to fluorescence emission of chlorophyll. The bar corresponds to a length of $10 \mu \mathrm{m}$.

Figure 3: Image of mixed 1 and 3 fluorescence emission channels (channel 1 attributed to fluorescence emission of B-phycoerythrin and channel 3 attributed to fluorescence emission of chlorophyll) obtained by CLSM from P.cruentum resuspension at 0.2 g dry biomass / $100 \mathrm{~mL}$ in deionized water and in $0.1 \mathrm{M}$ phosphate buffer at different $\mathrm{pH}$ and $\mathrm{NaCl}$ conditions. The bar corresponds to a length of 10 $\mu \mathrm{m}$. 
Figure 4: Image of mixed 1, 3 and 4 fluorescence emission channels (channel 1 attributed to fluorescence emission of B-phycoerythrin, channel 3 attributed to fluorescence emission of chlorophyll and channel 4 attributed to isolectin) obtained by CLSM from P.cruentum resuspension at $0.2 \mathrm{~g}$ dry biomass / $100 \mathrm{~mL}$ with addition of isolectin fluorescence probe in distilled water and in $0.1 \mathrm{M}$ phosphate buffer at different $\mathrm{pH}$ and $\mathrm{NaCl}$ conditions. The bar corresponds to a length of $10 \mu \mathrm{m}$.

Figure 5: Image of mixed 1, 3 and 4 fluorescence (when appropriate) emission channels (channel 1 attributed to fluorescence emission of B-phycoerythrin, channel 3 attributed to fluorescence emission of chlorophyll and channel 4 attributed to isolectin) obtained by CLSM from P.cruentum resuspension at $0.2 \mathrm{~g}$ dry biomass / $100 \mathrm{~mL}$ without and with addition of isolectin fluorescence probe in deionized water after one, two and three successive macerations. The bar corresponds to a length of $10 \mu \mathrm{m}$.

Figure 6: Image of mixed 1, 3 and 4 fluorescence (when appropriate) emission channels (channel 1 attributed to fluorescence emission of B-phycoerythrin, channel 3 attributed to fluorescence emission of chlorophyll and channel 4 attributed to isolectin) obtained by CLSM from P.cruentum resuspension at $1.5 \mathrm{~g}$ dry biomass / 100 deionized water: (A) control, (B) 70 MPa treatment, (C) 70+120 MPa treatment and (D) 70+120 MPa treated sample with addition of isolectin fluorescence probe. The bar corresponds to a length of $10 \mu \mathrm{m}$. 
Figure 1
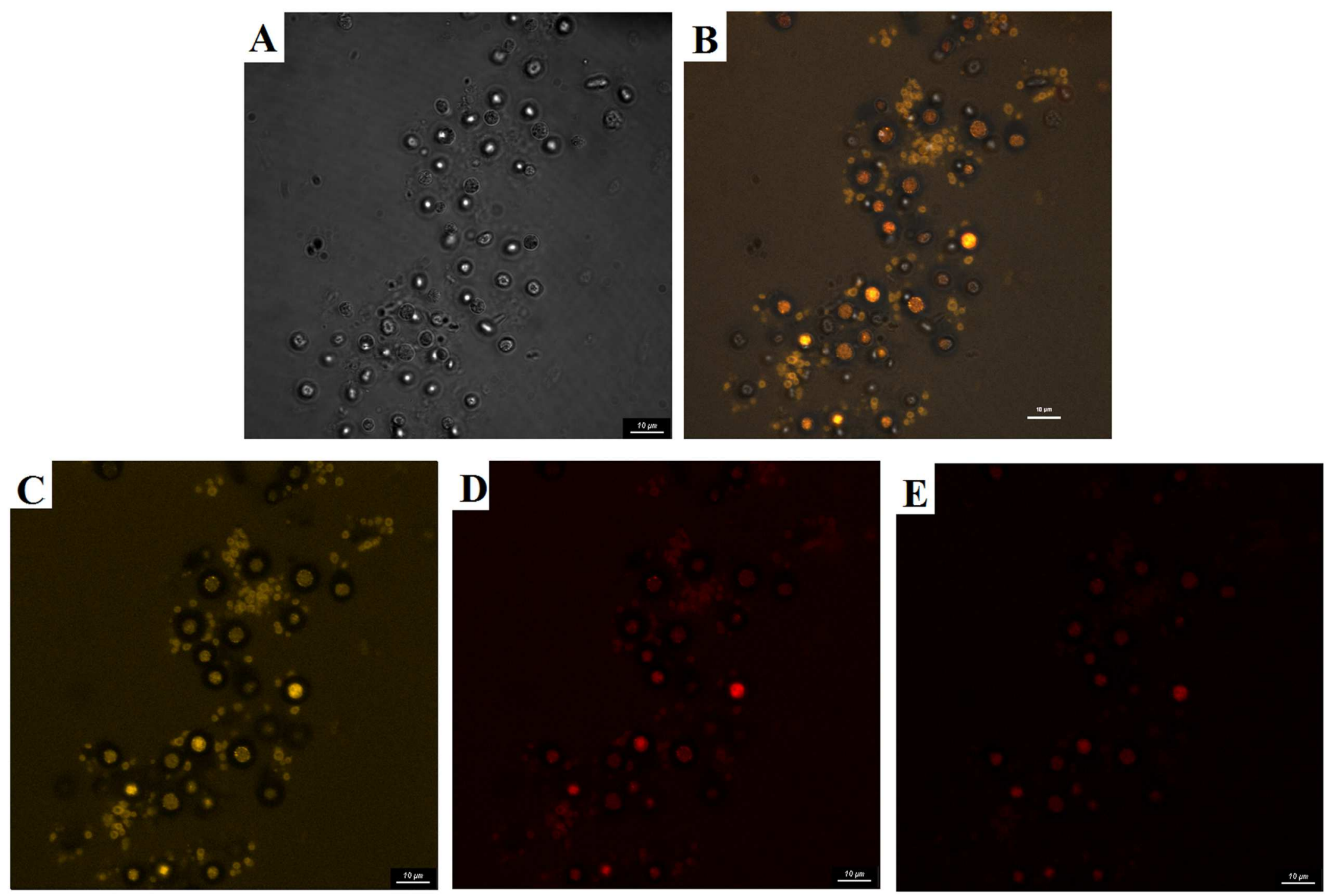
Figure 2

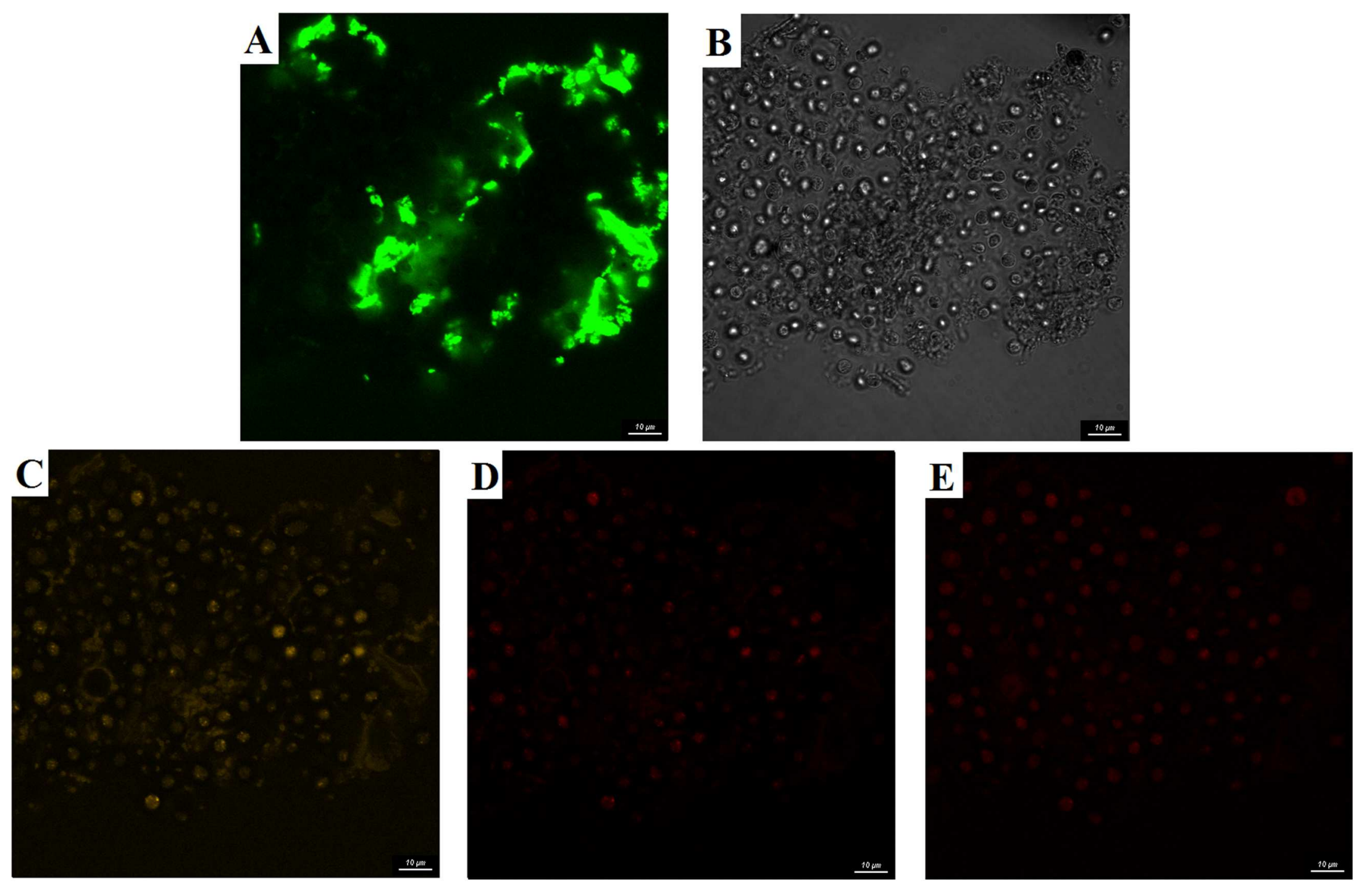


Figure 3

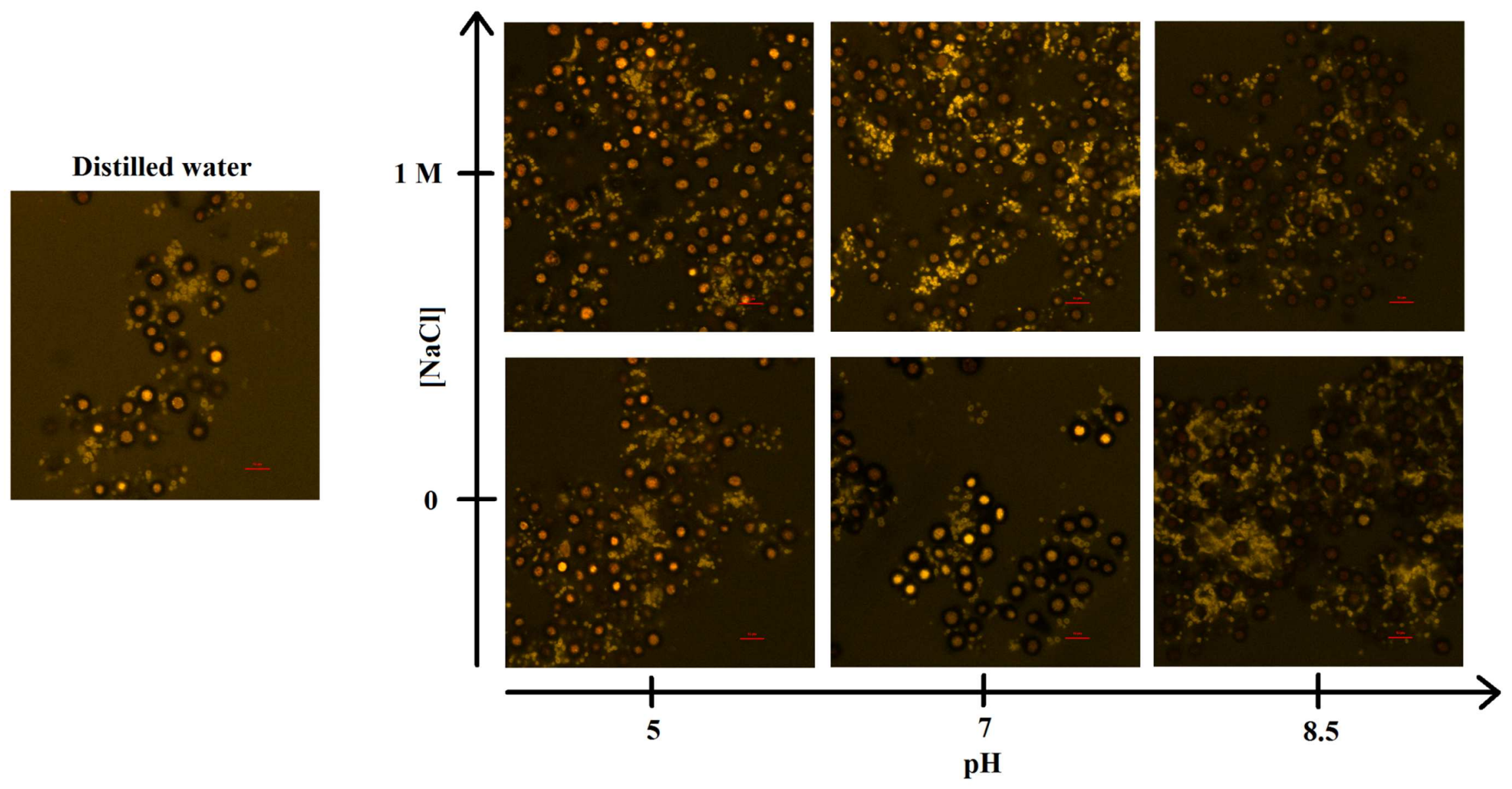

0.1 M phosphate buffer 
Figure 4

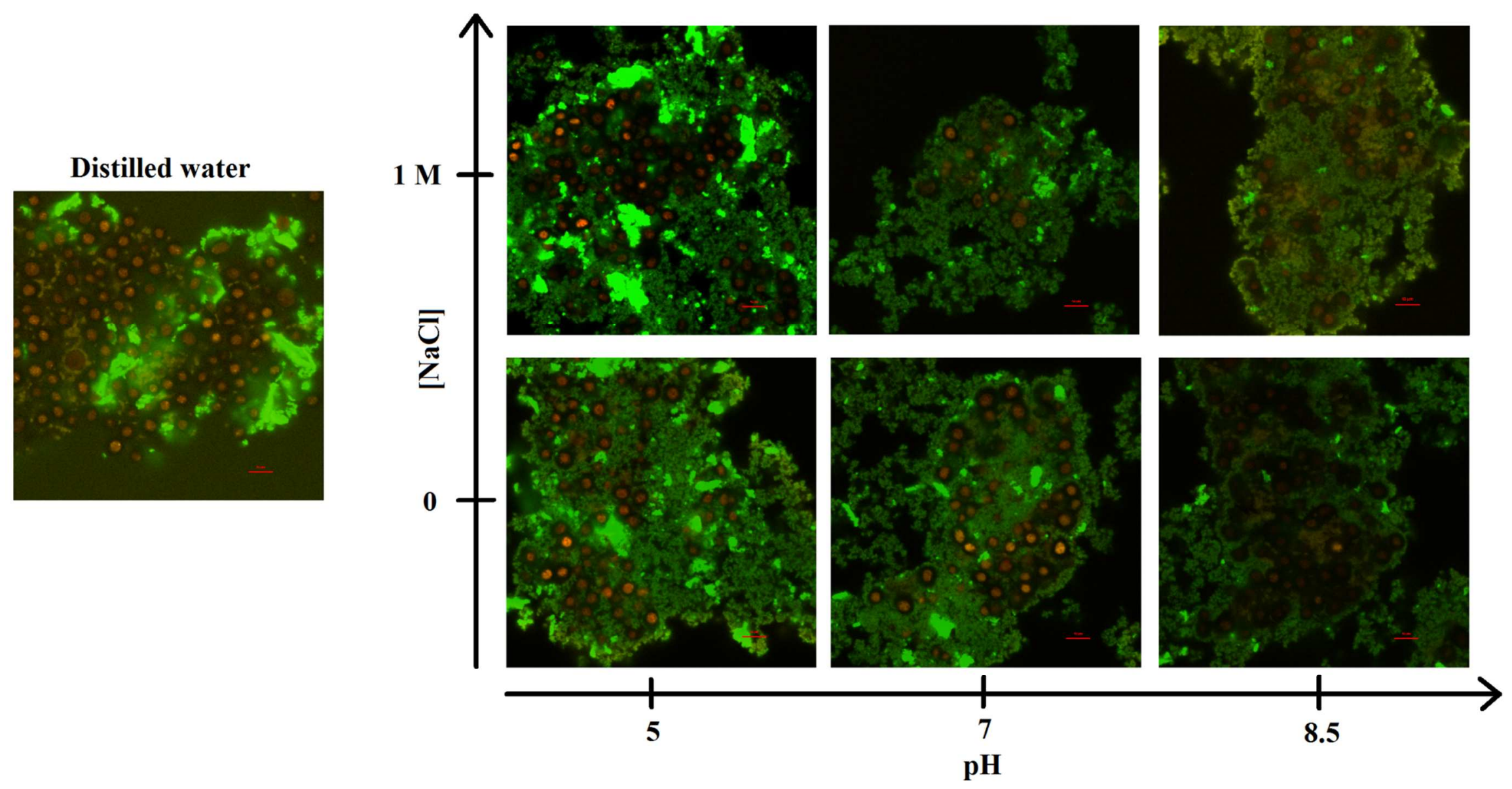

0.1 M phosphate buffer 
Figure 5





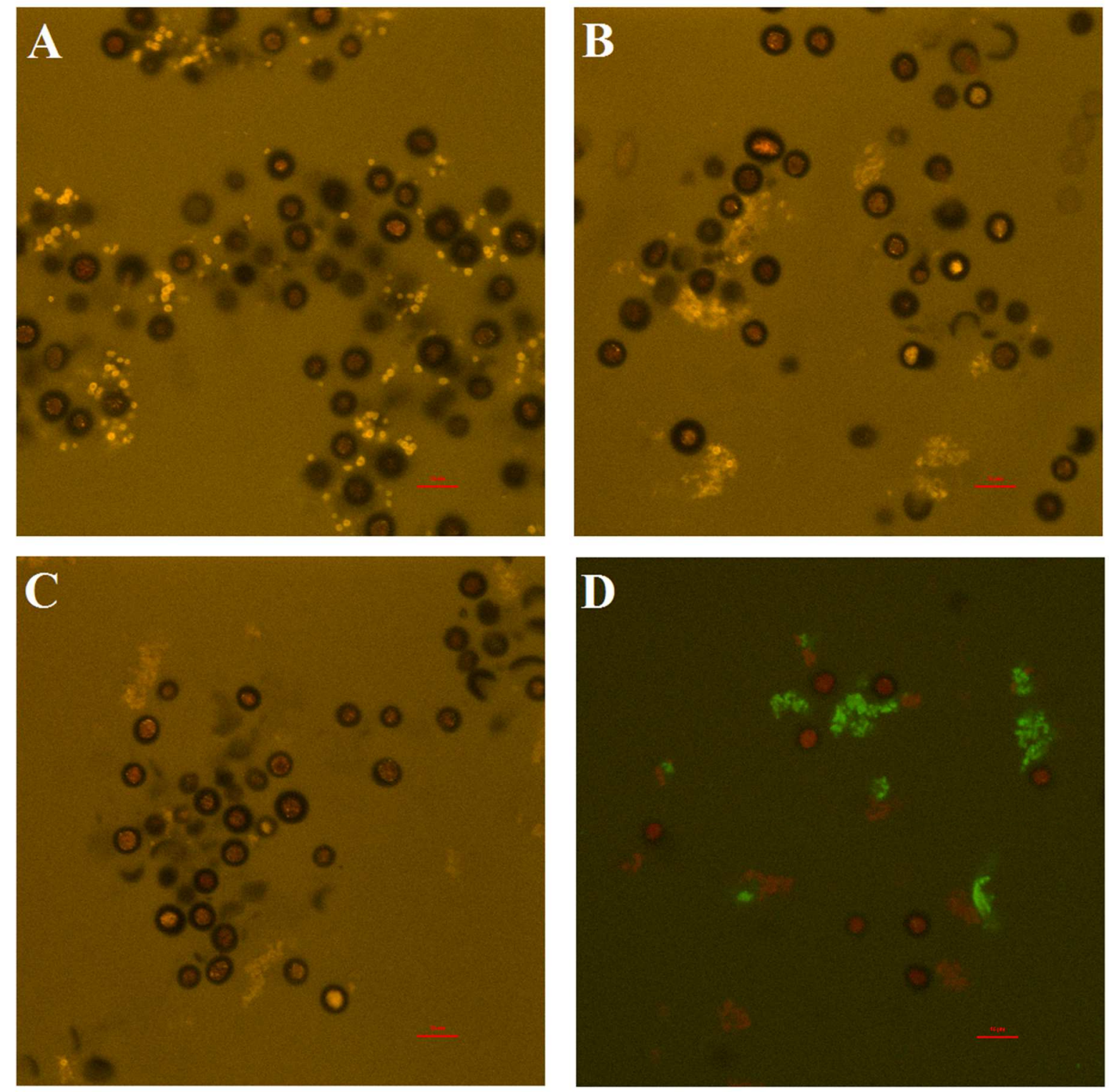
Table 1: Description of CLSM fluorescence emission channels

\begin{tabular}{|c|c|c|c|c|c|}
\hline Channel & $\begin{array}{l}\text { Detection } \\
\text { range }\end{array}$ & $\begin{array}{l}\text { Fluorescent } \\
\text { compound }\end{array}$ & $\begin{array}{l}\text { Maximum } \\
\text { fluorescence emission } \\
(\mathrm{nm})^{\mathrm{a}}\end{array}$ & $\begin{array}{l}\text { Laser } \\
\text { excitation } \\
(\mathrm{nm})\end{array}$ & Marked compound or structure \\
\hline 1 & $568-576 \mathrm{~nm}$ & B-phycoerythrin & 575 & 561 & \multirow{2}{*}{$\begin{array}{l}\text { Free or associated protein (phycobilisome) / } \\
\text { chloroplast [44] }\end{array}$} \\
\hline 2 & $639-647 \mathrm{~nm}$ & R-phycocyanin & 642 & 561 & \\
\hline 3 & $679-687 \mathrm{~nm}$ & Chlorophyll & 684 & 561 & Free or associated molecule / chloroplast [48] \\
\hline 4 & & Isolectin & 525 & 488 & $\begin{array}{l}\text { N-acetyl-D-galactosamine end groups and } \\
\text { terminal } \alpha \text {-D-galactosyl residues in } \\
\text { polysaccharides } \quad /\end{array}$ \\
\hline
\end{tabular}

a: according to $[8,44]$ for phycobiliproteins and [45-47] for chlorophyll and for [59] isolectin. 
Table 2: Average pH value, B-phycoerythrin content and purity index of sample supernatants \pm standard deviation. Data is shown as mean \pm standard deviation $(n=3)$. Grey lines separate the groups of samples involved in ANOVA ( 3 in total). Common letters indicate no significant difference between the values according to ANOVA $(p<0.05)$.

\begin{tabular}{|c|c|c|c|}
\hline Medium used for resuspensions & $\mathrm{pH}$ & $\begin{array}{l}\text { B-phycoerythrin } \\
\text { (mg/g dry biomass) }\end{array}$ & $\begin{array}{l}\text { Purity Index } \\
\text { (A545/A280) }\end{array}$ \\
\hline \multicolumn{4}{|l|}{$0.2 \mathrm{~g}$ dry biomass $/ 100 \mathrm{~mL}$ biomass in } \\
\hline Deionized water & $6.9 \pm 0.0^{\mathrm{e}}$ & $85 \pm 1^{\mathrm{a}}$ & $1.5 \pm 0.0^{\mathrm{abc}}$ \\
\hline $0.1 \mathrm{M}$ phosphate buffer $\mathrm{pH} 7$ & $7.1 \pm 0.0^{c}$ & $86 \pm 6^{\mathrm{a}}$ & $1.5 \pm 0.0^{\mathrm{a}}$ \\
\hline $0.1 \mathrm{M}$ phosphate buffer $\mathrm{pH} 5$ & $5.4 \pm 0.0^{\mathrm{f}}$ & $79 \pm 4^{a b c}$ & $1.5 \pm 0.0^{\mathrm{ab}}$ \\
\hline $0.1 \mathrm{M}$ phosphate buffer $\mathrm{pH} 8.5$ & $8.5 \pm 0.0^{\mathrm{a}}$ & $73 \pm 3^{c}$ & $1.3 \pm 0.0^{\mathrm{d}}$ \\
\hline $0.1 \mathrm{M}$ phosphate buffer $\mathrm{pH} 7$ with $1 \mathrm{M} \mathrm{NaCl}$ & $7.0 \pm 0.0^{\mathrm{d}}$ & $83 \pm 6^{\mathrm{ab}}$ & $1.5 \pm 0.0^{\mathrm{ab}}$ \\
\hline $0.1 \mathrm{M}$ phosphate buffer pH 5 with $1 \mathrm{M} \mathrm{NaCl}$ & $5.1 \pm 0.0^{\mathrm{g}}$ & $74 \pm 4^{c}$ & $1.4 \pm 0.0^{\mathrm{bc}}$ \\
\hline $0.1 \mathrm{M}$ phosphate buffer $\mathrm{pH} 8.5$ with $1 \mathrm{M} \mathrm{NaCl}$ & $8.3 \pm 0.0^{b}$ & $75 \pm 3^{b c}$ & $1.4 \pm 0.0^{\mathrm{c}}$ \\
\hline \multicolumn{4}{|l|}{$0.2 \mathrm{~g}$ dry biomass $/ 100 \mathrm{~mL}$ biomass in } \\
\hline Deionized water & $6.9 \pm 0.0^{\mathrm{a}}$ & $85 \pm 1^{\mathrm{a}}$ & $1.5 \pm 0.0^{\mathrm{a}}$ \\
\hline Second resuspension with deionized water & $6.8 \pm 0.0^{b}$ & $8 \pm 1^{b}$ & $0.8 \pm 0.0^{b}$ \\
\hline Third resuspension with deionized water & $6.7 \pm 0.0^{c}$ & $5 \pm 0^{\mathrm{c}}$ & $0.5 \pm 0.0^{\mathrm{c}}$ \\
\hline \multicolumn{4}{|l|}{$1.5 \mathrm{~g}$ dry biomass / $100 \mathrm{~mL}$ biomass in } \\
\hline Deionized water (untreated / control) & nd & $76 \pm 0^{a}$ & $1.0 \pm 0.0^{\mathrm{a}}$ \\
\hline $70 \mathrm{MPa}$ homogenizer treated sample & nd & $66 \pm 10^{a}$ & $0.8 \pm 0.1^{b}$ \\
\hline $70+120 \mathrm{MPa}$ homogenizer treated sample & nd & $48 \pm 9^{b}$ & $0.9 \pm 0.1^{b}$ \\
\hline
\end{tabular}

